\title{
EL CONCEPTO DE CONTRATO DE TRABAJO EN EL MARCO DEL CONVENIO DE LUGANO. COMENTARIO A LA SENTENCIA DEL TJUE DE 11 DE ABRIL DE 2019, ASUNTO C-603/17, BOSWORTH Y HURLEY.
}

\author{
THE CONCEPT OF EMPLOYMENT CONTRACT \\ IN THE LUGANO CONVENTION. COMMENTARY \\ OF THE JUDGEMENT OT THE CJEU AVRIL 11, 2019, \\ CASE C-603/17, BOSWORTH AND HURLEY.
}

\author{
CARMen VAQuero López \\ Profesora Contratada Doctora de Derecho internacional privado \\ Universidad de Valladolid
}

Recibido: 10.12.2019 / Aceptado: 17.12.2019

DOI: https://doi.org/10.20318/cdt.2020.5220

\begin{abstract}
Resumen: El TJUE se pronuncia, por primera vez, sobre el alcance de los foros de competencia judicial internacional en materia de contrato individual de trabajo del Convenio Lugano II. El paralelismo de este Convenio con el Reglamento Bruselas I se reproduce en esta decisión del Alto Tribunal, que sigue su jurisprudencia sobre la calificación del contrato de trabajo en el marco de las disposiciones del Reglamento europeo. Esta simetría no se ha mantenido tras la promulgación del Reglamento Bruselas I bis, por lo que la reciente decisión de los jueces de Luxemburgo pone sobre el papel la necesidad de una revisión del texto convencional.

Palabras clave: Convenio Lugano II, competencia judicial internacional, contrato de trabajo, acción procesal.

Abstract: The CJEU pronounces, for the first time, on the scope of the international jurisdiction regarding the individual employment contract of the Lugano II Convention. The parallelism of this Convention with the Brussels I Regulation is reproduced in this decision of the High Court, which follows its jurisprudence on the qualification of the employment contract within the framework of the provisions of the European Regulation. This symmetry has not been maintained after the promulgation of the Brussels I bis Regulation, so the recent decision of the Luxembourg judges puts on paper the need for a revision of the treaty text.
\end{abstract}

Keywords: Lugano II Convention, international jurisdiction, employment contract, legal action.

Sumario: I. Introducción. II. Los hechos litigiosos. III. Los foros de protección en materia de contratos de trabajo en el sistema del Convenio Lugano II. IV. El concepto de contrato de trabajo. V. La calificación de la acción procesal. VI. Valoración de la decisión del TJUE. 


\section{Introducción}

1. La decisión del TJUE de 11 de abril de 2019 en el asunto C-603/17, Bosworth y Hurley, constituye la primera decisión del Tribunal de Luxemburgo sobre la interpretación de los foros de competencia judicial internacional en materia de contrato individual de trabajo establecidos por los artículos 18 a 21 del Convenio de Lugano de 2007, relativo a la competencia judicial, el reconocimiento y la ejecución de resoluciones judiciales en materia civil y mercantil (en adelante, el Convenio Lugano II) ${ }^{1}$.

2. El sistema establecido en el marco del Convenio Lugano II para la protección procesal de los trabajadores se corresponde con el instaurado en el ámbito de la UE por los artículos 18 a 21 del Reglamento Bruselas I, también referidos a los contratos individuales de trabajo. Este paralelismo alcanza igualmente a la interpretación de las disposiciones de ambos instrumentos, por mor de lo establecido en el Protocolo número 2 del Convenio Lugano II. De conformidad con lo dispuesto en este Protocolo, el TJUE será el garante de la uniformidad en la interpretación de las disposiciones de ambos instrumentos, de manera que la jurisprudencia del Alto Tribunal sobre la interpretación de las disposiciones del Reglamento europeo será aplicable a las disposiciones del Convenio Lugano II .

Sin embargo, este acercamiento entre los dos regímenes de competencia judicial internacional se transforma en distancia por lo que se refiere a los contratos individuales de trabajo, pues las importantes modificaciones introducidas por el Reglamento Bruselas I bis respecto de esta materia (arts. 20 a 23) no encuentran paralelismo en el Convenio Lugano II.

3. La decisión del TJUE en el asunto Bosworth y Hurley ofrece una buena oportunidad para analizar el sistema de competencia judicial internacional del Convenio Lugano II en materia de contrato individual de trabajo y pone sobre el papel la necesidad de llevar a cabo una revisión del mismo que, cuando menos, acerque las soluciones convencionales al régimen del Reglamento Bruselas I bis.

\section{Los hechos litigiosos}

4. Los hechos que dieron lugar a la decisión del TJUE en el asunto Bosworth y Hurley son los siguientes.

Los Sres. Peter Bosworth y Colin Hurley, nacionales británicos con domicilio en Suiza, fueron demandados ante la High Court of Justice (England \& Wales) Queen's Bench Division, por el accionista único de Arcadia (Farahead Holdings Ltd.) y las sociedades de este grupo multinacional (Arcadia London, Arcadia Switzerland y Arcadia Singapure), para obtener una indemnización por el perjuicio causado como consecuencia de una serie de operaciones fraudulentas en las que se habían visto envueltas dichas sociedades.

Los demandados, que ostentan la condición de chief executive officer (CEO) y de chieffinancial officer (CFO) del Grupo Arcadia -del que también son consejeros- y están vinculados a las sociedades demandantes por un "contrato de trabajo", interpusieron una declinatoria de competencia ante los tribunales británicos, por considerar que únicamente los tribunales suizos pueden conocer de un litigio que entra dentro del ámbito de aplicación de los artículos 18 a 21 del Convenio Lugano II, donde se recogen los foros especiales en materia de contratos individuales de trabajo.

La demanda inicial se basaba en las imputaciones de maquinación a través del uso de medios ilícitos, de incumplimiento del deber de actuar en beneficio de otro y de incumplimiento de obligaciones contractuales expresas o implícitas derivadas de los contratos de trabajo que vinculaban a los demandados con el Grupo Arcadia. Más tarde, con posterioridad a la declinatoria de competencia interpuesta por los Sres. Bosworth y Hurley, los demandantes modificaron su demanda y renunciaron a alegar el incumplimiento contractual. En estas nuevas circunstancias, el tribunal británico se declaró competente

\footnotetext{
${ }^{1}$ DOUE L 339 de 21 de diciembre de 2007.

2 Vid. G. Palao Moreno, "La competencia judicial internacional en materia de contratos individuales de trabajo en el Convenio de Lugano", Revista de Trabajo y Seguridad Social, octubre 2019, pp. 115-140.
} 
para conocer de las cuestiones delictuales, según la calificación del Derecho inglés, e incompetente para decidir respecto de los hechos que habían tenido lugar cuando los demandados estaban vinculados con los demandantes por un contrato de trabajo.

5. La decisión del tribunal británico fue recurrida por los Sres. Bosworth y Hurley en apelación ante la Court of Appeal (England \& Wales) (Civil Division) y, posteriormente, en casación ante la Supreme Court of the United Kingdom, que decidió suspender el procedimiento y plantear ante el TJUE cuatro cuestiones prejudiciales. Mediante estas cuestiones se pide del Alto Tribunal un pronunciamiento sobre la interpretación que debe darse al concepto de contrato individual de trabajo en el marco los artículos 18 a 21 del Convenio Lugano II, así como sobre si estos preceptos son de aplicación a una demanda de indemnización por daños presentada entre las partes de un contrato sobre la base de un fundamento jurídico de naturaleza delictual.

\section{Los foros de protección en materia de contratos de trabajo en el sistema del Convenio Lugano II}

6. Los artículos 18 a 21 del Convenio Lugano II establecen un sistema especial de competencia judicial internacional para la protección de los trabajadores que están inmersos en un litigio afectado por un elemento de internacionalidad, que resulta de aplicación cuando el demandado -ya sea el trabajador o el empresario- tiene su domicilio en un Estado miembro de la AELC (Islandia, Noruega y Suiza) o se prorroga la competencia de los tribunales de uno de estos Estados. En virtud de lo establecido en dichas disposiciones, se limita el ejercicio de la autonomía de la voluntad de las partes en la elección del tribunal internacionalmente competente y se modula el juego de los foros de competencia judicial en función de su posición procesal en el litigio, reconociendo al trabajador un forum actoris que se deniega al empresario demandante.

7. Efectivamente, de conformidad con lo dispuesto en el artículo 21 del Convenio Lugano II, los acuerdos de elección de tribunal en el marco de un contrato de trabajo únicamente se permiten si se celebran con posterioridad al nacimiento del litigio o, en cualquier momento, si incrementan las posibilidades de acción del trabajador demandante. En defecto de cláusula de jurisdicción válida, los artículos 18 a 20 del instrumento convencional establecen un sistema de foros de competencia subsidiarios que maximizan la protección del trabajador, al incrementar sus opciones procesales frente a las del empresario. De este modo, el trabajador podrá demandar al empresario, bien ante los tribunales del lugar donde éste tiene su domicilio, bien ante los tribunales del lugar en el que el trabajador desempeñare habitualmente su trabajo o en el que lo hubiere desempeñado en último lugar; en su defecto, cuando resultare imposible determinar un único lugar de prestación laboral habitual, el trabajador podrá optar entre el foro general del domicilio del empresario demandado y el del lugar en el que estuviere o hubiere estado situado el establecimiento del empleador (art. 19). Todo ello sin perjuicio de la posibilidad, reconocida al trabajador por el artículo 18 del Convenio Lugano II, de interponer su demanda ante los tribunales del lugar donde el empresario posee un establecimiento secundario (ex. art. 5.5), siempre que se cumplan las condiciones relativas a la entidad de la agencia y a su actividad autónoma. Sin embargo, las posibilidades procesales del empresario son mucho mas reducidas, pues únicamente podrá demandar al trabajador ante los tribunales en los que éste tuviera su domicilio (art. 20).

8. Este sistema de competencia judicial internacional, especialmente tuitivo, se corresponde con el establecido por los artículos 18 a 21 del Reglamento Bruselas I, pero este paralelismo se rompe a partir de la promulgación del Reglamento Bruselas I bis, cuyos artículos 20 a 23 introducen importantes reformas en materia de contrato individual de trabajo, que no han sido reproducidas en el espacio Lugano.

En particular, el Reglamento Bruselas I bis añade un nuevo foro de competencia judicial internacional, permitiendo al trabajador interponer su demanda ante los tribunales del lugar "desde el que el trabajador" desempeña habitualmente su trabajo [art. 22.1.b).i)]; reconoce el alcance universal de los foros de protección a favor del trabajador, que serán aplicables en todos los supuestos en los que éste sea 
el demandante, con independencia del país donde el empresario tenga su domicilio (art. 21.2); protege al trabajador de los efectos de una comparecencia involuntaria ante los tribunales del Estado miembro UE donde el empresario interpone su demanda, pues el juez, antes de asumir su competencia, debe asegurarse de que el trabajador demandado ha sido informado de su derecho a impugnar la competencia ante dicho tribunal y de las consecuencias de comparecer o no (art. 26.2); corrige la regla general de litispendencia (prior tempore, potior iure) cuando el demandante es un trabajador y el acuerdo atributivo de competencia no es válido conforme al sistema del propio Reglamento (art. 31.4); admite el litisconsorcio pasivo de empresarios ex artículo 8.1 (art. 20.1); y contempla la vulneración de los foros de protección en materia de contrato individual de trabajo como causa de denegación del reconocimiento de la sentencia cuando el demandado en el proceso de origen haya sido el trabajador [art. 45.1.e)] ${ }^{3}$.

9. Ninguna de estas nuevas reglas puede aplicarse en el espacio Lugano, por lo que la decisión del TJUE en el asunto Bosworth y Hurley ofrece una buena oportunidad para llamar la atención sobre la conveniencia de llevar a cabo una revisión del Convenio Lugano II, actualmente vigente, que favorezca el tradicional paralelismo con las soluciones del sistema de Bruselas ${ }^{4}$. Pero, sobre todo, la decisión del Alto Tribunal vuelve a plantear la necesidad de introducir un concepto autónomo del contrato de trabajo en el marco de las normas de competencia judicial internacional, que permita una calificación materialmente orientada de la relación que se establece entre las partes del contrato, una calificación funcional que tenga en cuenta la ratio indiscutiblemente tuitiva de los foros de protección adoptados en este ámbito $^{5}$. Esta misma finalidad deberá servir también para delimitar el alcance de las acciones que pueden subsumirse en el ámbito de aplicación de los foros de competencia judicial internacional en materia de contrato individual de trabajo establecidos por ambos sistemas, una cuestión sobre la que el TJUE no se pronuncia, pero que fue planteada por las partes del litigio principal en el asunto que nos ocupa y ha merecido una especial atención del Abogado General.

\section{EI concepto de contrato de trabajo}

10. La finalidad de las disposiciones contenidas en los artículos 18 a 21 del Convenio Lugano II es la de proteger procesalmente al trabajador en los litigios que lo enfrentan al empresario, en tanto que parte económica y jurídicamente más débil de la relación contractual establecida entre ellos. Sin embargo, a diferencia de lo que sucede en materia de contratos celebrados con consumidores, en torno a los cuales el Convenio Lugano II también articula un sistema especialmente protector sobre la base de una delimitación objetiva de la persona tutelada (art. 15) ${ }^{6}$, en materia de contratos de trabajo ninguna disposición de este Convenio precisa lo que deba entenderse ni por contrato de trabajo, ni por trabajador,

\footnotetext{
${ }^{3}$ Para una sistematización de las novedades introducidas por el Reglamento Bruselas I bis en materia de contrato individual de trabajo, vid. A.-L. Calvo Caravaca, J. Carrascosa (dirs.) y C. CaAmiña Domínguez, Litigación internacional en la Unión Europea. Competencia judicial y validez de resoluciones en materia civil y mercantil en la Unión Europea. Comentario al Reglamento Bruselas I bis, Cizur Menor, Aranzadi, 2017, pp. 426-428. También sobre estas reformas, vid. N. Nord, "Refonte du règlement «Bruxelles I» et protection du travailleur”, La Semaine Juridique. Édition Sociale, no 52, 2014, pp. 22-28.

${ }^{4}$ Ampliamente, vid. J. MASEDA Rodríguez, "Competencia judicial internacional, reconocimiento y ejecución de resoluciones judiciales en materia civil y mercantil. La convivencia del Reglamento 1215/2012 con el Convenio de Lugano de 2007”, Revista General de Legislación y Jurisprudencia, nº 3, 2018, pp. 365-423, esp. pp. 388-389.

${ }^{5}$ En el mismo sentido, vid. M. A. AdAm MuÑoz, "Algunas consideraciones en torno al contrato individual de trabajo en el Derecho internacional privado" en M. SABIDo RodríGuez (Coord.), Algunos retos que plantea la realidad social, económica y jurídica actual en los ámbitos societario y laboral, Cizur Menor, Aranzadi, 2012, pp. 282-283.

${ }^{6}$ Este carácter "objetivo" del concepto de consumidor utilizado en las normas europeas de competencia judicial internacional ha sido recientemente remarcado por el TJUE en su sentencia de 3 de octubre de 2019, asunto C-208/18, Petruchová. Para el Alto Tribunal, el elemento determinante para la aplicación de los foros de protección en materia de contratos de consumidores del Reglamento Bruselas I bis no es la finalidad del contrato, sino el hecho de que el consumidor actúe al margen de un actividad profesional, siendo irrelevante cualquier otra circunstancia subjetiva que concurra en esta persona, como por ejemplo los eventuales conocimientos o su experiencia en la materia sobre la que versa el contrato. Sobre esta decisión, vid. J. I. PAREDES PÉrez, "La noción de consumidor a efectos de la aplicación de los foros de protección del Reglamento de Bruselas I bis a litigios relativos a instrumentos financieros y de inversión”, La Ley Unión Europea, no 75, 2019.
} 
a los efectos de aplicación de las normas especiales de competencia judicial internacional establecidas por este instrumento.

11. Así sucede también en el marco del sistema de Bruselas, lo que ha obligado al TJUE ha pronunciarse sobre la calificación del contrato de trabajo en el ámbito que nos ocupa. En su sentencia de 10 de septiembre de 2015, asunto C-47/14, Holterman, el Alto Tribunal defendió una interpretación autónoma del contrato de trabajo y estableció que los foros de protección del Reglamento Bruselas I (entonces en vigor) únicamente serán de aplicación cuando la persona en cuyo favor se invocan haya realizado, durante cierto tiempo, en favor de dicha sociedad y bajo la dirección de ésta, determinadas prestaciones a cambio de las cuales reciba una retribución ${ }^{7}$. En el litigio principal del que trae causa esta decisión, la sociedad neerlandesa Holterman se enfrentaba con el Sr. Spies von Büllesheim, residente en Alemania y demandado en su condición de administrador social por desempeñar incorrectamente sus funciones, así como por incurrir en dolo o imprudencia consciente en el cumplimiento del contrato de trabajo que lo vinculaba con dicha sociedad. En estas circunstancias, similares a las que concurren en los demandados en el asunto que ahora nos ocupa, los jueces de Luxemburgo hacen depender la calificación de una relación contractual como "contrato de trabajo", de la existencia de una relación de subordinación entre las partes, determinando que esta circunstancia debe apreciarse en cada caso concreto, en función del conjunto de hechos y circunstancias que caractericen a las relaciones inter partes.

12. En definitiva, el TJUE parte de una aproximación funcional a las circunstancias del caso concreto, que obliga a diferenciar el lenguaje jurídico utilizado por las partes, por un lado, y la finalidad perseguida por la relación jurídica establecida entre ellas, por otro. De esta manera, el elemento determinante que se tiene en cuenta para declarar la aplicabilidad al caso concreto de los foros establecidos para la protección de los trabajadores es la función que cumple el contrato entre las partes, con independencia de los términos utilizados para designar la relación que se establece entre ellas ${ }^{8}$.

Esta misma calificación es la que sigue el TJUE en el asunto Bosworth y Hurley. En su decisión de 11 de abril de 2019, el Alto Tribunal señala que "un contrato que vincula a una sociedad y a una persona fisica que ejerce las funciones de consejero de la misma no crea un nexo de subordinación entre ellas y, en consecuencia, no puede tener la calificación de 'contrato individual de trabajo', en el sentido

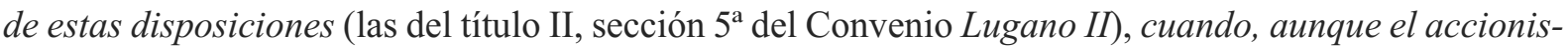
ta o los accionistas de esta sociedad tengan la facultad de poner fin a dicho contrato, esa persona esté en condiciones de decidir o decida efectivamente los términos de ese contrato y disponga de un poder de control autónomo tanto sobre la gestión corriente de los asuntos de esa sociedad como sobre el ejercicio de sus propias funciones".

13. Siguiendo su jurisprudencia Holtermann, el TJUE hace depender la calificación del contrato de trabajo de la existencia de una relación de subordinación entre las partes, sin que la terminología utilizada para definir las relaciones que se establecen entre ellas sea determinante? 9

\footnotetext{
${ }^{7}$ Sobre esta decisión y, en general, sobre la interpretación por parte del TJUE de las normas europeas de competencia judicial internacional en materia de contratos de trabajo, vid. J. F. LousADa Arochena: "Competencia xudicial internacional e persoal de embaixadas, auxiliares de voo e outras cuestións en litixios laboráis (Últimas aportacións doTribunal de Justiza da Unión Euroepa), Revista Galega de Dereito Social, nº 7, 2018, pp. 99-126, esp. pp. 115-122.

${ }^{8}$ Sobre esta calificación funcional del contrato de trabajo en el sistema de Bruselas, vid. C. VAQuero López, "Mecanismos de Derecho internacional privado europeo para la protección de los trabajadores en supuestos de deslocalización de empresas", Anuario Español de Derecho Internacional Privado., t. XVII, 2017, pp. 425-471, esp. pp. 437-441.

${ }^{9}$ Ya en el informe JenARD/MöLler sobre el Convenio de Lugano de 1988 se señalaba que una relación laboral supone en todo caso la existencia de un "vínculo de dependencia del trabajador con respecto al empleador" (DOCE C 189 de 28 de julio de 1990). En el mismo sentido, en sus Conclusiones Generales al asunto Holterman, el Abogado General CruZ VilLALÓN señalaba que, al interpretar de forma autónoma el concepto de contrato individual de trabajo a los efectos del Reglamento, no debe perderse de vista el fin protector de la parte más débil de la relación que está en la base de la creación por el legislador de los criterios específicos de atribución de la competencia judicial en este ámbito (apartado 27). El elemento diferenciador que separa el contrato de trabajo de la prestación de servicios a los efectos del Reglamento viene constituido por el hecho de que, en el caso del contrato de trabajo, la persona que presta el servicio esté sometida, en mayor o menor grado, al poder de dirección y a las instrucciones de la otra parte de la relación contractual, lo que la coloca en una posición de subordinación respecto a ésta. Es
} 
14. Se ha criticado que, en el asunto Bosworth y Hurley, el TJUE en ningún momento se haya planteado una interpretación favorable a una parte que aparentemente tiene una posición más débil desde una perspectiva económica y jurídica, más aún cuando tanto el demandante como el demandado admiten que existe una relación labora ${ }^{10}$. Sin embargo, la calificación del contrato de trabajo no puede hacerse depender de una apariencia, ni de cómo se denomina la relación entre las partes, sino que está en función de la ratio del sistema en cuyo marco se pretende una protección especial para el trabajador. Efectivamente, el alcance de la protección que se otorga al trabajador es diferente en el ámbito de las disposiciones sobre competencia judicial internacional, cuya alta función tuitiva justifica la exigencia de un plus de subordinación entre las partes, a la que tiene en otro ámbitos, como en el de la determinación del Derecho material aplicable al contrato, donde no puede hablarse de normas materialmente orientadas a tutelar al trabajador ${ }^{11}$. Tampoco podrá tomarse en consideración la interpretación del concepto de "subordinación" adoptada por el TJUE en su jurisprudencia Danosa y Balkaya", referida a la libre circulación de trabajadores, que extiende la protección contra el despido que ofrecen las directivas de armonización de la UE a los directivos de las sociedades; tal y como tal señala el Abogado General en sus conclusiones generales (apdo. 58), los intereses en juego en el ámbito de las normas sobre competencia judicial internacional para determinar la responsabilidad de los trabajadores frente a sus empleadores (Derecho laboral) son muy diferentes de los que existen en materia de determinación de la responsabilidad civil de los directivos (Derecho de sociedades), y, por tanto, no pueden extrapolarse.

15. En consecuencia, atendiendo a las circunstancias del caso concreto, los Sres. Bosworth y Hurley no podrán prevalerse de la protección que le otorgan los artículos 18 a 21 del Convenio Lugano II y, por consiguiente, la determinación de los tribunales internacionalmente competentes para conocer del litigio principal del que trae causa la decisión del TJUE que nos concierne deberá hacerse de conformidad con las reglas generales de competencia judicial internacional establecidas por dicho instrumento. Ello significa que, en ausencia de una prorrogación tácita o expresa de la competencia judicial internacional a favor de los tribunales de otro Estado, con carácter general serán competentes para conocer del presente litigio los tribunales del domicilio del demandado (ex art. 2) o, alternativamente, los tribunales designados por los foros de competencia especiales de los artículos 5 y 6 del Convenio Lugano II.

\section{La calificación de la acción procesal}

16. Mediante la primera cuestión prejudicial planteada ante el TJUE, el tribunal británico pide su pronunciamiento sobre el criterio que debe seguirse para determinar si una acción ejercitada por un empresario frente a un empleado o antiguo empleado puede considerarse una acción "en materia de contrato individual de trabajo" en el sentido de los artículos 18 a 21 del Convenio Lugano II. El Alto Tribunal considera improcedente responder a esta cuestión, pues su planteamiento se basa en la hipótesis de que los contratos en causa sean calificados como contratos de trabajo, una calificación a la que, como hemos visto, el Tribunal se opone.

esa posición de subordinación, señala el Abogado General, la que hace necesaria una protección particular de la parte más débil y justifica las reglas especiales del Reglamento europeo (apartado 28). El autor insiste en que el criterio de la subordinación es determinante para identificar una relación laboral, si bien es necesaria una "relectura flexible" de este requisito, en J. CRUZ VILLALÓn, "El concepto de trabajador subordinado frente a las nuevas formas de empleo", Revista de Derecho Social, n 83 , 2018, pp. 13-44, esp. pp. 33-35.

$10 \mathrm{Vid}$. A. Espiniella MenÉndez, "Convenio de Lugano y concepto de contrato de trabajo de personal directivo", La Ley, $\mathrm{n}^{\mathrm{o}} 6659,2019$.

11 Vid. C. Vaquero López, "Mecanismos de Derecho internacional....", loc. cit., pp. 452-461.

${ }^{12}$ Sentencias del TJUE de 11 de noviembre de 2010, asunto C-232/09, y de 9 de julio de 2015, asunto C-229/14. Un amplio análisis de esta jurisprudencia puede encontrarse en B. Alonso-Olea García, "Los conceptos de trabajador por cuenta ajena, asegurado social y ciudadano de la Unión Europea según la jurisprudencia del Tribunal de Justicia de la Unión Europea. Sus consecuencias y su controversia”, Revista Española de Derecho Europeo, nº 62, 2017. 
17. Sin embargo, el interés de la cuestión nos obliga a plantearnos cuál habría sido la decisión de los jueces de Luxemburgo si entre las partes del litigio hubiera existido una relación laboral en un supuesto, como el planteado en el litigio principal, en el que la demanda, modificada para excluir los incumplimientos del contrato, tuviera como objeto el ejercicio de una acción extracontractual por el daño causado por los demandados.

18. Con carácter general, la calificación de una acción como contractual o extracontractual a los efectos de determinar los tribunales internacionalmente competentes debe realizarse conforme a la jurisprudencia Brogsitter ${ }^{13}$, según la cual esta calificación debe basarse en los hechos que sustentan la demanda y no en el fundamento jurídico material que invoca el demandante ${ }^{14}$. Esta calificación es especialmente delicada cuando existe una vinculación contractual entre las partes, tal y como sucede en el asunto que ahora nos ocupa. En estos casos, la delimitación de la naturaleza de la acción debe hacerse depender del carácter que tiene la obligación que sirve de base a la demanda, con independencia de cuál sea la calificación de la acción en el Derecho nacional. De este modo, si la fuente de la obligación no se halla en el acuerdo de voluntades, sino en un hecho ilícito y es consecuencia de la infracción de una obligación legal, el litigio debe ser calificado como materia extracontractual ${ }^{15}$.

19. Esta calificación, basada en los antecedentes del hecho litigioso y no en los fundamentos jurídicos materiales invocados por el demandante, es también la que debe primar en un asunto como el que nos ocupa y sobre la que debe fundamentarse la aplicación de los artículos 18 a 21 del Convenio Lugano II, cuyas disposiciones, especialmente tuitivas, no pueden ser eludidas por el empresario basando su pretensión en cuestiones delictuales. Así lo ha entendido nuestra doctrina cuando señala que los litigios referidos a la responsabilidad por daños producidos en el marco de la relación laboral entre el trabajador y el empresario deben subsumirse dentro de los foros de protección en materia de contratos individuales de trabajo del Reglamento Bruselas I (paralelos a los del Convenio Lugano II), y ello aunque conforme a la ley aplicable al fondo la acción pueda calificarse como extracontractual ${ }^{16}$.

20. En consecuencia, tal y como señala el Abogado General en las conclusiones al asunto que nos ocupa (apdo. 94), una demanda versa sobre la materia "contratos individuales de trabajo" cuando, a la luz de los hechos, existe un determinado vínculo material entre la demanda y el contrato, tal y como particularmente sucede cuando la demanda tiene por objeto una controversia que tiene su origen en la relación contractual, con independencia de que el demandante base o no su demanda en dicho contrato.

21. De este modo, la demanda de indemnización interpuesta contra los Sres. Bosworth y Hurley estaría sometida al sistema establecido por los artículos 18 a 21 del Convenio Lugano II si su objeto hubieran sido las faltas cometidas por los demandados en el desempeño de sus funciones como trabajadores. Una interpretación en este sentido tiene como consecuencia la exclusión del ámbito de aplicación de dichos preceptos de las demandas del empresario contra el trabajador relativas a un comportamiento lesivo que no esté relacionado con ninguna circunstancia objetiva (lugar, tiempo, medios o finalidad) de las funciones desempeñadas por el trabajador.

${ }^{13}$ STJUE de 13 de marzo de 2014, asunto C-548/12, Brogsitter, con nota de C. I. Cordero Álvarez, REDI, vol. LXVI, $\mathrm{n}^{\mathrm{o}}$ 2, 2014, pp. 250-253. Sobre la evolución de esta jurisprudencia y, muy particularmente, sobre la decisión del TJUE de 14 de julio de 2016 en el asunto C-196/15, Granarolo, con la que el Alto Tribunal complica la labor de delimitación de las materias contractual y extracontractual, vid. I. ANTÓN JuÁrez, "Los retos de la litigación transnacional en la Unión Europea: ¿Se ha extendido demasiado la 'noción de materia contractual' en el Reglamento Bruselas I?", Cuadernos de Derecho Transnacional, vol. $10, \mathrm{n}^{\mathrm{o}} 1,2018$, pp. 525-533.

${ }^{14}$ Interpretación defendida con anterioridad en su sentencia de 27 de septiembre de 1988, asunto 189/87, Kalfelis.

$15 \mathrm{Vid}$. J. C. Fernández Rozas y S. SÁnchez Lorenzo, Derecho internacional privado, $10^{\mathrm{a}}$ Ed., Cizur Menor, Aranzadi, 2018, pp. 675-676.

${ }^{16}$ En este sentido vid. M. Virgós Soriano y F. J. Garcimartín Alférez, Derecho procesal civil internacional. Litigación internacional, $2^{\text {a }}$ Ed., Cizur Menor, Aranzadi, 2007, p. 178. 


\section{Valoración de la decisión del TJUE}

22. La decisión del TJUE en el asunto Bosworth y Hurley merece, en nuestra opinión, una valoración positiva en la medida en que extiende, al ámbito de aplicación del Convenio Lugano II, su jurisprudencia sobre la interpretación del concepto de "contrato individual de trabajo" en el marco de las disposiciones de competencia judicial internacional del Reglamento Bruselas I. Los jueces de Luxemburgo insisten en que el elemento determinante que identifica al trabajador beneficiario de dichas disposiciones es que la actividad que lleva a cabo está sometida, en mayor o menor grado, al poder de dirección y a las instrucciones del empresario, de manera que se coloca en una posición de subordinación respecto de éste. Es esta característica de "subordinación" la que justifica la necesidad de una especial tutela en el ámbito procesal de quien ocupa una posición económica y jurídicamente más débil.

23. Esta delimitación del ámbito de aplicación de los foros de protección en materia de contrato de trabajo favorece el paralelismo inicial entre el Reglamento Bruselas I y el Convenio Lugano II, pero pone de manifiesto la falta de correspondencia entre las soluciones actualmente aplicables en el espacio Bruselas y las vigentes en el territorio Lugano, lo que obliga a plantear la conveniencia de su revisión, lo cual permitiría reforzar la finalidad tuitiva de dichos foros.

24. Por otra parte, en la decisión que es objeto de comentario, el TJUE insiste en la necesidad de utilizar un concepto autónomo de contrato de trabajo en los sistemas de Bruselas y de Lugano, que tenga en cuenta la "función social", especialmente tuitiva, de las normas de competencia judicial internacional adoptadas en el ámbito laboral. Una solución en este sentido permite además sostener una concepción flexible del contrato de trabajo, de forma que la mera integración del trabajador en la esfera organizativa, productiva y directiva de la empresa sea suficiente para que podamos hablar de "subordinación", con independencia de cuál sea el nombre que recibe la relación entre las partes implicadas. De este modo, se garantiza una aplicación eficiente de los foros de protección en materia de contrato individual de trabajo, evitando su elusión por los empresarios cuando los elementos esenciales de la relación laboral se desdibujan.

25. En definitiva, la decisión del TJUE favorece una aplicación materialmente orientada de las normas de competencia judicial internacional en materia de contrato de trabajo del Convenio Lugano II, que se compadece con la heterogénea realidad de las relaciones laborales en un mercado de trabajo globalizado y flexible. 